\title{
Controlling coal rock massif hydro-treating process by instrumental and geophysical methods
}

\author{
Vladimir Klishin ${ }^{1,2}$, Alexander Shadrin ${ }^{1 *}$, and Alexander Teleguz ${ }^{1}$ \\ ${ }^{1}$ The Federal Research Center of Coal and Coal Chemistry of Siberian Branch of the Russian \\ Academy of Sciences, 10 Leningradskey Ave., Kemerovo city 650065, Russia \\ ${ }^{2}$ T.F. Gorbachev Kuzbass State Technical University, 28 Vessenniaya, Kemerovo city 650000 , \\ Russia
}

\begin{abstract}
Coal rock massif hydro-treating methods accompanied by crack initiation and propagation under influence of injected fluid pressure and applied for preventing gas-dynamic phenomena are studied in the article. The perspectives of applying acoustic methods for controlling the process of crack formation and effective preventive measures are also studied.
\end{abstract}

\section{Introduction}

With increasing the depth of coal mining and crossing the frontiers that divide the coal seams according to dynamic and gas-dynamic phenomena manifestation danger, the necessity to apply rock bumps and coal outbursts preventive measures which require both current control of the coal massif properties changes and further control of the effectiveness for selecting optimal methods and their parameters appear.

Hydro-treating of a coal rock massif is widely applied for controlling coal roofs during longwall mining and also for coal seam relief and degassing intensification by means of creating an artificial crack or a network of cracks in roof rocks and coals. The practices of applying directional hydraulic fracturing and hydro-treating of coal seams at Kuzbass mines can be read about in our works published within the period of $2017-2020$.

At present, at Kuzbass mines, directional hydraulic fracturing method that helps to solve different technological tasks is applied. These tasks are: decreasing the initial and subsequent main roof caving increments [1,2]; decreasing rock heaving [3] under the influence of the stope bearing pressure; increasing the stability of inter-lava pillar and the preserved working face [4]; decreasing ground pressure on the support of the preliminary mined out or formed break-down chamber. The idea of directional hydraulic fracturing method is in creating an extended directional crack under the influence of the injected liquid in lithified hard roof rocks.

To prevent the dynamic and gas-dynamic phenomena, to create crack network in coal and to change stress state and moistening of a coal layer local and regional methods of hydro-treating are applied.

${ }^{*}$ Corresponding author: avsh-357@mail.ru 
The hydro-treating methods are: low-pressure soaking and moistening of a coal seam and a coal seam hydro-ploughing. They are applied as local and regional measures for preventing rock bumps and sudden outbursts [5].

The effectiveness of the hydro-treating methods, which are not accompanied by crack formation process such as low-pressure soaking and low-pressure moistening of a coal seam, is estimated on the bases of a coal seam moisture content indicator or by applying instrumental methods of the current forecasting of rock bumps and outburst danger. The effectiveness of a coal seam hydro-ploughing and hydraulic fracturing accompanied by crack formation is defined by both instrumental and geophysical methods [5], which allow registering the fact of a crack growing and propagation, and a change in a coal rock massif stress state.

The purpose of the work is to substantiate the necessity to improve the quality of hydrotreating control by means of simultaneous application of instrumental and geophysical methods.

\section{Instrumental methods for controlling hydro-treating of a coal rock massif}

Instrumental methods for controlling the effectiveness of a coal seam hydro-treating include the forecasting procedure that uses the data on initial gas-emission rate and drill fines output [5]. The following steps can be referred to instrumental control of the process for creating the extended directional crack in coal seam roof by means of directional hydraulic fracturing (DHF) method:

1. Monitoring working fluid pressure during the fluid injection. Short-term bouncing of a manometer arrow indicates that there are artificial cracks formation in a massif: newly formed artificial cracks are filled with the working fluid, the volume of the fluid that enters into the crack increases sharply and the pressure, registered by the manometer, which is installed into the hydro-system near the borehole mouth, falls for a short period of time.

2. Monitoring the flow of the working fluid into a free working face surface out of the adjoining directional hydraulic fracturing wells and boreholes drilled for setting the deeplaid roof bolts or benchmark stations allow estimating the radius of DHF crack propagation.

3. Video-endoscopic survey of the control boreholes for defining the depth of the DHF crack opening.

The general disadvantage of all the above-mentioned instrumental methods of controlling the crack-formation in roof rocks and coal is in the absence of procedure that estimates a coal seam selvage and adjoining rocks stress state. To estimate the rearrangement of the ground pressure in a DHF crack possible influence zone is possible using the data on monitoring the manometer readings. The manometers are installed into the powered support unit during the weakening of the main roof in the vicinity of the stope.

For lessening the following-up roof-caving increment and preventing its overhanging in the mined-out space at the airway joining point 16-21, the DHF method was applied at "Yubileinaya" Mine. Figure 1 demonstrates the scheme for DHF boreholes placing.

In the main roof rocks of coal seam 16 with the thickness from 20 to $27 \mathrm{~m}$, consertal siltstones with the power of 9, according to Protodiyakonov scale, and honestones with the power of 9-12 are deposited. According to a caving rate, the roof can be referred to a medium- or a hard caving one. The mining depth is from $475 \mathrm{~m}$ to $780 \mathrm{~m}$. Airway 16-21 is supported by roof bolting applying deep-laid rope bolts. The main and immediate roof overhanging in the mined-out space over the airway reaches $30 \mathrm{~m}$ and it allows a part of the air of the ventilating flow to be flown out into the mined-out space. To prevent the 
overhanging the DHF scheme with inclined cut-off holes drilled with $60^{\circ}$ turn towards the stope (see fig.1 and fig. 2) was applied.

Before and after the hydraulic fracturing in boreholes No. 1-3, the pressure readings at manometers of 15 powered support units of the stope were registered. After the hydraulic fracturing, the roof pressure at the canopy of the first three support units (up to $4.5 \mathrm{~m}$ from adjoining with airway 16-21) decreased on 30-40 percent and at the other 12 units the pressure increased (further the measuring was not carried out). The support unit step is 1.5 $\mathrm{m}$. During the hydro-treating and measuring, the works on coal excavation and shifting the powered support unit didn't take place.

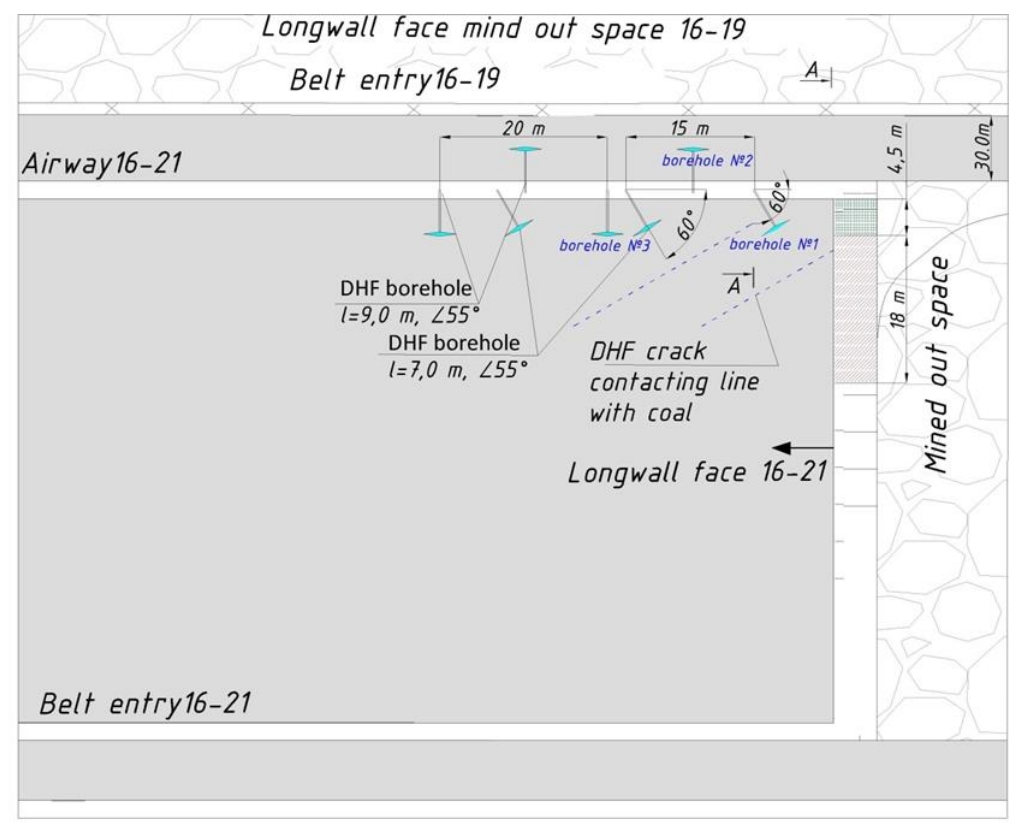

Fig. 1. The scheme for DHF boreholes placing in 16-21 airway

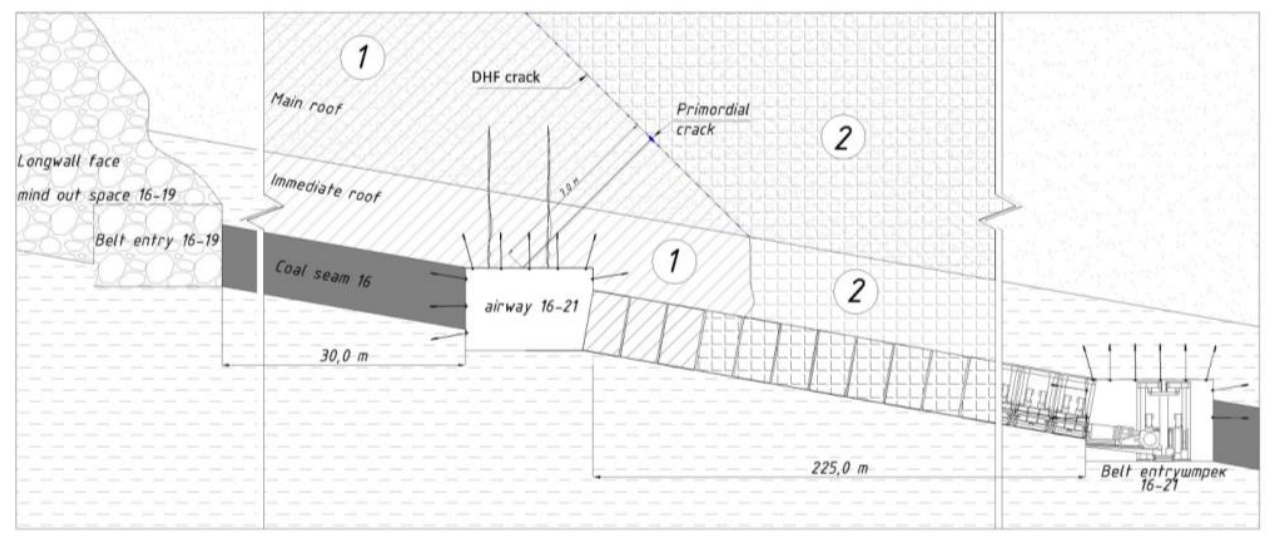

Fig. 2. The scheme of ground pressure spreading over the powered support unit props after DHF in borehole 1. 
As far as the stope advanced, the main roof console, hanging over the junction of the stope with the airway, propped on selvage and a pillar. DHF crack divided the overhanging console into two parts (see fig.2). The left part (1) with the lesser weight "rested" on interlava pillar, the console part (2) with higher weight "rested" on the selvage of a stope This can explain the increase of the emulsion pressure in the powered support props at the distance from $4.5 \mathrm{~m}$ and $22.5 \mathrm{~m}$ from the airway. The caving of the roof rocks in a minedout space over airway 16-21 at the researched area followed during the advancing of the stope and the pressure in powered support props leveled.

The fact of relieving the coal seam selvage in the airway and rearranging of the ground pressure proves that the DHF crack went along the given trajectory. However, in the process of stoping of the working area the manometer readings at the powered support props can not be visually and continuously controlled. It can be done by means of automated pressure measuring of the manometers. An example of arranging such control is Marco dynamic phenomena forecasting system. Continuous pressure measuring in support props and its further analysis is fulfilled with the help of Marco electric-hydraulic management system "Digital Mine" (Robotic Mining) [6, 7].

\section{Geophysical methods for controlling hydro-treating of a coal rock massif}

The methods that allow monitoring the dynamics of changing the stresses and cracks propagation in coal and adjacent rocks are referred to geophysical methods:

- a method of seismic tomography with building seismographic sections for speed performance distribution of seismic waves passage along the whole length of the extracted pillar [8];

- spectral-acoustic method; the idea of this method is in defining the ratio between high frequency and low frequency amplitude of the acoustic signal spectrum generated in rock massif [9];

- acoustic emission method which estimates the crack propagation intensity in the rock massif [9].

Seismic tomography method allows defining low and excessive fissuring zones at the surveyed area outlined by the workings and these zones are characterized by corresponding maximal and minimum velocity of the seismic waves passing. Using the results of the seismic tomography, the distribution and intensity zones of fissuring after hydro-treating of the part of the massif situated between the receiver of the artificial acoustic signal and its source can be estimated. The given method covers a vast area and can be used when estimating the hydro-treating effectiveness of the long-length boreholes drilled for preliminary methane drainage and/or for further soaking [10]. The disadvantage of this method is in the point that the surveyed massif should be outlined by the acting workings. In case the surveyed section of the massif is a pillar between the mined-out space and the development heading of the neighboring lava it is better to use acoustic emission method for estimating the fissuring process during the hydro-treating.

Under acoustic emission intensity, the number of the "jumps" of the growing crack per unit time is understood [11]. The growing crack emits acoustic vibrations. After registering these vibrations, the correspondence of the hydraulic parameters (pressure and fluid injection rate) to the required values can be judged about. It allows both estimating the effectiveness and controlling fissuring in the process of hydro-treating. When using the pumping unit with hard performance characteristics, the following ways for controlling fluid injection modes can be used [12]:

- experimental selection of a borehole filtering part length according to the chosen hydro-treating mode with applying different method of sealing the borehole mouth; 
- releasing a part of fluid from the pump outlet on intake;

- simultaneous hooking up of several boreholes for reducing the fluid pressure and consumption in each borehole;

- subsequent hooking up of two pumping units for increasing fluid pressure and consumption.

About the length of the DHF crack can be judged according to the number of the acoustic emission impulses registered during injecting the working fluid into the initiating crack using the equation [9]:

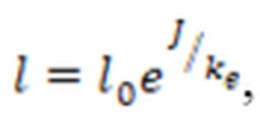

Where $l$ is a hydraulic fracturing crack length, $\mathrm{m}$;

$l_{0}$ - initial length of the crack (diameter of the initiating crack);

$j$ - number of acoustic emission impulses;

$k_{e}$-non-dimensional coefficient, defined according to the results of the experimental injection

The detailed information about defining the connection between acoustic emission parameters and coal rock massif hydro-treating parameters can be found in paper [12].

To estimate the stresses in the enclosing rocks the spectral-acoustic method is used. The method is based on analyzing the spectrum of the acoustic signal that is generated by a combined machine cutting tool or a drilling device into the rock massif. The coefficient of relative stresses is the estimation criterion of a massif limit stresses. It is defined as an amplitudes relation of high- frequency and low-frequency parts of spectrum $[13,14]$.

Physical bases of the spectral-acoustic method is in the issue that the attenuation coefficient of acoustic vibrations at the first approximation is linearly proportionate to the vibration frequency and inversely proportionate to average stresses that act along the vibration propagation path [15]. Hereof it follows that with the growth of the stresses the attenuation coefficient of high-frequency harmonics reduces faster comparing to lowfrequency one. That is why the relation of high-frequency and low-frequency harmonics amplitudes increases with the growth of the stresses. There are two variants of spectralacoustic method performance and they differ in the selection of low-frequency and highfrequency subranges of the applied frequencies. The peculiarities of these two variants are studied in paper [15] in detail. A significant disadvantage of both variants are in incomplete acoustic spectrum processing. That is why if when approaching to a dangerous section of a coal-seam the signal spectrum change takes place, in the frequency area situated between low-frequency and high-frequency subranges, the danger might not be registered. To avoid this error the spectral-acoustic method modification that uses the whole continuous spectrum of amplitude-frequency characteristic (method of controlling amplitude-frequency characteristic median) has been offered [15].

\section{Conclusion}

As it is seen from all above-mentioned, to control promptly the coal rock massif hydrotreating and to estimate its effectiveness two acoustic methods showed their potential. They are the acoustic emission method and the spectral-acoustic method. To reduce the amount 
of the equipment that is necessary for implementing both methods it is advisable to unite these controlling methods into a single package. With this purpose a technical assignment for designing experimental portable apparatus that uses acoustic emission method for controlling hydro-treating process and spectral-acoustic method, based on measuring amplitude frequency characteristic median of artificial signal for estimating stress state of a massif with the enclosing rock has been worked out.

Funding

The research was carried out due to the grant of Russian Science Foundation (project \#17-17-01143).

\section{References}

1. Instruction on selecting the method and parameters of the roof weakening at the extraction areas, 102 (Leningrad: Ministry of the USSR coal industry. Scientific Research Institute of mining geomechanics and mining survey, 1991)

2. V.I. Klishin, G.Yu. Opruk, A.V. Sentyurev, A.V. Nikolayev Ugol', 11, 12 (2015)

3. V.I. Klishin, G.Yu. Opruk, P.V. Grechishkin, Ye. Yu. Rozonov, V.N. Shcherbakov Ugol', 10, 35 (2019)

4. A.S. Teleguz Annual conference for young scientific researchers of FRC CCC SB RAS "Razvitiye -2020" [electronic source] 79 (Kemerovo: FRC CCC SB RAS 2020)

5. The Instruction on forecasting dynamic phenomena and monitoring rock massif during coal deposit mining (Federal Service for Ecological, Technological and Atomic Supervision (Order No 515 on 10 December, 2020))

6. M. Reuter, M. Crash, W. Kiessling, Yu. Veksler High Technology for the Development and Utilizing Mineral Resources, 4, 17 (2018)

7. M. Reuter, M. Crash, K Meikhoffer, W. Kiessling, Yu. Veksler High Technology for the Development and Utilizing Mineral Resources, 33 (2015)

8. O.V. Tailakov, M.P. Makeev, S.V. Sokolov High Technology for the Development and Utilizing Mineral Resources, 6, 38 (2020)

9. A.V. Shadrin, A.S. Teleguz Bulletin of Research Center for Safety in Coal Industry/Industrial Safety, 3, 10 (2017)

10. V. I. Klishin, O. V. Taylakov, G. Yu. Opruk, M. P. Makeev, S. V. Sokolov, A. S. Teleguz and A. L. Tatsienko IOP Conference Series: Earth and Environmental Science "International Scientific and Research Conference on Knowledge-based technologies in development and utilization of mineral resources 1-7 (SibSIU, Novokuznetsk, 2019)

11. V.A. Greshnikov, Yu. B. Drobot Acoustic emission. Application for materials and products testing, 272 (Moscow: Izdatel'stvo standartov, 1976)

12. A.V. Shadrin, A.S. Teleguz The Bulletin of Kuzbass State Technical University, 4, 5 (2019)

13. The procedures for carrying out acoustic sounding of a rock massif applying hardware and software suite, 36, (Moscow: MNTL RIVAS, 2016)

14. S.V.Mirrer, O.I Khmara, A.V. Shadrin Spectral-acoustic prediction of coal seam outburst danger, 92 (Kemerovo: Kuzbassvuzizdat, 1999)

15. A.V. Shadrin, A.A. Kontrimas, A.S. Teleguz High Technology for the Development and Utilizing Mineral Resources, 4, 371 (2018) 